\title{
Novos registros para a família Melastomataceae nos Estados do Paraná e Santa Catarina, Brasil
}

\author{
Fabrício Schmitz Meyer ${ }^{1,3}$, Julia Meirelles ${ }^{1}$, Mayara Krasinski Caddah ${ }^{1}$ e Renato Goldenberg ${ }^{2}$
}

Recebido: 4.10.2011; aceito: 21.06.2012

\begin{abstract}
New records to the Melastomataceae family to Paraná and Santa Catarina States, Brazil). The genus Henriettea DC. were recorded for the first time in Santa Catarina State, as well as four species of Melastomataceae: Henriettea glabra (Vell.) Penneys, Michelangeli, Judd \& Almeda, Leandra tetraquetra (Cham.) Cogn., Miconia racemifera (DC.) Triana and Miconia paniculata (DC.) Naudin. Miconia paniculata and Salpinga margaritacea (Naudin) Triana are also recorded for the first time for Paraná State, and the latter is confirmed for Santa Catarina State, since its occurrence was previosly recorded based in an old and flowerless collection. All these species have their distribution limits extended towards the south, reaching the Paraná and Santa Catarina States. Descriptions, illustrations and taxonomic comments for all these new records are provided.
\end{abstract}

Key words: Henriettea, Leandra, Miconia, Salpinga, taxonomy

RESUMO - (Novos registros para a família Melastomataceae nos Estados do Paraná e Santa Catarina, Brasil). Neste trabalho são registradas uma nova ocorrência de gênero Henriettea DC. para Santa Catarina e quatro novas ocorrências de espécies de Melastomataceae para esse Estado: Henriettea glabra (Vell.) Penneys, Michelangeli, Judd \& Almeda, Leandra tetraquetra (Cham.) Cogn., Miconia racemifera (DC.) Triana e Miconia paniculata (DC.) Naudin. Miconia paniculata e Salpinga margaritacea (Naudin) Triana são também registradas pela primeira vez para o Estado do Paraná, e confirma-se a ocorrência da última no Estado de Santa Catarina, mencionada anteriormente de forma duvidosa, com base em uma coleta antiga e sem flores. Todas essas espécies tiveram seus limites de distribuição ampliados no sentido sul, alcançando os Estados do Paraná e Santa Catarina. São fornecidas descrições, ilustrações e comentários taxonômicos para as novas ocorrências. Palavras-chave: Henriettea, Leandra, Miconia, Salpinga, taxonomia

\section{Introdução}

Melastomataceae é uma família com distribuição pantropical, representada por cerca de 150-166 gêneros e 4.570 espécies (Clausing \& Renner 2001). Na região neotropical, onde está localizado o centro de diversidade da família, podem ser encontradas cerca de 3.000 espécies (Renner 1993, Martins 2009a). Melastomataceae está bem representada nas diversas formações vegetacionais dos Estados de Santa Catarina e do Paraná, e grande parte das espécies ocorre em Floresta Ombrófila Densa e formações associadas (Wurdack 1962, Goldenberg 2004).

Para o Estado de Santa Catarina já existe um tratamento taxonômico para Melastomataceae
(Wurdack 1962), embora a família ainda não disponha de fascículo na coleção Flora Ilustrada Catarinense. Wurdack (1962) mencionou 116 espécies para o Estado, incluídas em 13 gêneros. No Estado do Paraná já foram realizados estudos taxonômicos para diversos gêneros de Melastomataceae (Goldenberg 2004, Goldenberg et al. 2005, Camargo \& Goldenberg 2007, Camargo et al. 2009, Meyer et al. 2010, Meyer \& Goldenberg 2012, Rechetelo dados não publicados, Morais dados não publicados), faltando apenas tratamentos taxonômicos para os gêneros Behuria Cham., Huberia DC. e Mouriri Aubl.

A maioria das espécies de Melastomataceae que ocorrem nos Estados do Paraná e de Santa Catarina distribui-se ao longo da Serra do Mar do Brasil, que se

1. Universidade Estadual de Campinas, Instituto de Biologia, Pós-Graduação em Biologia Vegetal, Caixa Postal 6109, 13083-970 Campinas, SP, Brasil

2. Universidade Federal do Paraná, Setor de Ciências Biológicas, Departamento de Botânica, Caixa Postal 19031, 81531-970 Curitiba, PR, Brasil

3. Autor para correspondência: schmitzmeyer@gmail.com 
extende desde o Estado da Bahia até Santa Catarina, enquanto um número menor de espécies possui distribuição ampla, ocorrendo também em outras partes da América Tropical (Wurdack 1962, Martins 2009a).

As informações apresentadas neste trabalho resultam de coletas de campo e consultas recentes a herbários dos Estados de Santa Catarina e do Paraná, onde puderam ser confirmados registros inéditos de táxons de Melastomataceae. São fornecidas descrições e ilustrações destes táxons, além de comentários taxonômicos que visam auxiliar a identificação.

\section{Material e métodos}

Para este estudo foram consultadas as coleções de Melastomataceae depositadas nos herbários FURB, HBR, JOI, MBM e UPCB (Thiers continuamente atualizado). Também foram realizadas expedições a campo para coleta de material botânico nos municípios de São Francisco do Sul e São Bento do Sul, localizados em Santa Catarina. Depois de coletados, os materiais foram preparados segundo a metodologia usual de herborização (Fidalgo \& Bononi 1984) e as duplicatas depositadas nos herbários JOI e UPCB.

As espécies foram identificadas por meio de comparação com acervos de herbários e com base em bibliografia especializada (Cogniaux 1883-1888, Cogniaux 1891, Wurdack 1962, Goldenberg 2004, Camargo \& Goldenberg 2007, Silva \& Baumgratz 2008, Baumgratz 2009, Baumgratz \& Souza 2009, Camargo et al. 2009, Goldenberg 2009, Martins 2009b), e descritas com base nos materiais examinados, complementando-se, quando necessário, com material examinado adicional, procedente de outros Estados.

Com relação à morfologia, o número de nervuras primárias das folhas foi complementado com sinal de "mais" e o número dois quando constatada a ocorrência de um par submarginal tênue adicional (p.ex., 3+2 nervuras, com 3 nervuras acródromas principais conspícuas e mais o par tênue). Com relação à disposição, as nervuras foram classificadas como: basais - nervuras com inserção na base da lâmina; suprabasais - inserção de um ou mais pares laterais acima da base da lâmina; e confluentes - para nervuras unidas.

Para a confirmação de dados de distribuição das espécies utilizaram-se o Catálogo de Plantas e Fungos do Brasil (Baumgratz et al. 2010) e a Flora
Fanerogâmica do Estado de São Paulo (Martins 2009a), que estão mais atualizados.

Informações sobre o relevo, clima e vegetação do Estado do Paraná foram obtidas em Maack (2002), Goldenberg (2004) e Ambiente Brasil (2010) e , para Santa Catarina, em Klein (1978, 1979, 1980), Junior (1991) e Ambiente Brasil (2010).

\section{Resultados e Discussão}

Neste trabalho são registradas a nova ocorrência do gênero Henriettea DC. para o Estado de Santa Catarina, e quatro novas ocorrências de espécies de Melastomataceae para esse Estado: Henriettea glabra (Vell.) Penneys, Michelangeli, Judd \& Almeda, Leandra tetraquetra (Cham.) Cogn., Miconia racemifera (DC.) Triana e Miconia paniculata (DC.) Naudin. Também é confirmada a ocorrência de Salpinga margaritacea (Naud.) Triana em Santa Catarina, anteriormente mencionada de forma duvidosa para esse Estado, com base em uma coleta antiga e desprovida de flores (Wurdack 1962).

Para o Estado do Paraná registra-se a nova ocorrência de Miconia paniculata (DC.) Naudin, não mencionada no último tratamento taxonômico para o gênero nesse Estado (Goldenberg 2004), e também de Salpinga margaritacea.

Henriettea glabra (Vell.) Penneys, F.A. Michelangeli, Judd \& Almeda, Syst. Bot. 35(4): 797. 2010.

Figura $1 \mathrm{a}-\mathrm{b}$

Árvores, 5-8 m alt.; ramos circulares a subquadrangulares glabros. Pecíolo 1,5-2,8 cm compr.; lâmina 11,2-20 × 3,8-9 cm, subcoriácea, oblonga ou elíptica, ápice agudo ou acuminado, base atenuada ou aguda, glabra em ambas as faces, nervuras 3 ou $3+2$, primeiro par lateral suprabasal. Inflorescência em fascículos paucifloros, bráctéolas ausentes. Flores 5-meras; pedicelo 0,7-1 cm compr.; hipanto ca. 4,6 mm compr., glabrescente; cálice com lacínias internas truncadas, externas inconspícuas; pétalas brancas, triangulares, ca. $5 \mathrm{~mm}$ compr.; estames 10 , isomorfos, filetes ca. 2,2 mm compr., anteras ca. 2,7 mm compr., ápice arredondado, poro único; ovário 5-locular; estilete $5,5 \mathrm{~mm}$ compr. Fruto bacáceo, nigrescente, com cálice persistente, 4,7-5,5 × 3,6-4,7 mm.

Material examinado: BRASIL. SAnta Catarina: Guabiruba, Morro Santo Antônio, 12-II-2002, M. Sobral \& L. Sevegnani 9524 (FURB, MBM).

Material adicional examinado: BRASIL. EsPíRITo SAnto: Cariacica, Reserva Biológica de Duas Bocas, 
20-VII-2008, A.M.A. Amorim et al. 7587 (UPCB); Santa Teresa, Reserva Biológica de Nova Lombardia, 20-II-2002, L. Kollmann et al. 5595 (UPCB).

Espécie endêmica do Brasil, até então registrada apenas para os Estados do Espírito Santo, Rio de Janeiro e São Paulo (Baumgratz 2010), sendo este o primeiro registro para o Estado de Santa Catarina e, portanto, para o sul do Brasil.

Leandra tetraquetra (Cham.) Cogn. in Mart., Fl. Bras. 14(4): 112. 1886.

Figura $1 \mathrm{c}-\mathrm{d}$

Arbustos, 1,5-3,5 m alt.; ramos jovens quadrangulares, densamente recobertos por tricomas dendríticos ou estrelados 0,2-0,4 mm compr. Pecíolo 1,7-3,2 cm compr.; lâmina 8,8-14,2 × 4,7-7,3 cm, cartácea, oval, ápice agudo ou acuminado, base obtusa ou oblíqua, margem denticulada, face adaxial com tricomas escabrosos 0,5-0,7 mm compr., face abaxial com tricomas estrelado-estipitados 0,1-0,5 mm compr., nervuras $5+2$, primeiro e segundo pares laterais suprabasais. Inflorescência em panícula, ca. $10,7 \times 8,9 \mathrm{~cm}$; brácteas ca. $23,8 \mathrm{~mm}$ compr., bractéolas 2-12,8 mm compr. Flores 5-meras; hipanto 3-3,5 mm compr., tricomas dendríticos ca. $1 \mathrm{~mm}$ compr., cálice com lacínias internas 1,2-1,4 mm compr., triangulares, lacínias externas 2-2,3 mm compr., linear-triangulares; pétalas brancas ou róseas, ca. $3 \mathrm{~mm}$ compr.; estames 10 , conectivo inapendiculado, anteras 2,8-3,2 mm compr., róseas; ovário ínfero, 3-locular, ápice seríceo; estilete glabro, ca. $6,5 \mathrm{~mm}$ compr. Fruto bacáceo, 4,6-5,1 × 3,7-4,2 mm.

Material selecionado: BRASIL. SANTA CATARINA: São Bento do Sul, Morro da Igreja, 10-IX-2008, F.S. Meyer 791 (JOI, UPCB).

Leandra tetraquetra ocorre nos Estados de Minas Gerais, Rio de Janeiro e Paraná (Souza \& Baumgratz 2010), sendo este o primeiro registro para o Estado de Santa Catarina. Difere das demais espécies de Leandra que ocorrem nesse Estado principalmente pelos ramos quadrangulares. Também se destacam as folhas com a face adaxial revestida por indumento escabroso, com tricomas de base alargada, e face abaxial com tricomas estrelado-estipitados.

Miconia paniculata (DC.) Naudin, Ann. Sci. Nat. Bot., sér. 3, 16: 245. 1850.

Arbustos, 1,5-2 m alt.; ramos, pecíolo, inflorescência e hipanto com tricomas estrelados ou furfuráceos de ca. 0,2 mm compr. Pecíolo 0,8-1,3 cm compr.; lâmina 4,9-9,7 × 1,7-3,2 cm, cartácea, lanceolada a oval-lanceolada, ápice caudado ou acuminado, base obtusa, margem denteada-ondulada, face adaxial glabra ou com tricomas estrelados ca. 0,1 mm compr. na região sobre as nervuras primárias e folhas jovens, face abaxial com tricomas estrelados ou furfuráceos ca. 0,2 mm diâm., nervuras $3+2$, basais, unidas por pequena membrana na face abaxial. Inflorescência em panícula, $2-5,5 \mathrm{~cm}$ compr.; brácteas e bractéolas ca. 0,6 mm compr., lanceoladas, persistentes. Flores 5-meras; hipanto ca. 1,3 mm compr., cálice com lacínias internas inconspícuas, lacínias externas ca. $0,5 \mathrm{~mm}$ compr., triangulares, persistentes; pétalas ca. 1,7 mm compr., obovadas, ápice obtuso ou emarginado; estames 10, conectivo prolongado ca. $0,2 \mathrm{~mm}$ compr., com calcar basal arredondado, dorsalmente disposto, anteras 0,9-1,1 mm compr., poro único; ovário 2-3-locular, ápice glabro; estilete ca. $3 \mathrm{~mm}$ compr. Fruto não visto.

Material examinado: BRASIL. PARANÁ: Tunas do Paraná, Estrada para Tunas, 21-IV-2007, E. Camargo et al. 101 (UPCB). Santa Catarina: Angelina, Rio do Meio, 20-V-2009, S. Dreveck \& F.E. Carneiro 895 (FURB).

Miconia paniculata ocorre nos Estados da Bahia, Rio de Janeiro e São Paulo (Goldenberg 2010), sendo este o primeiro registro para os Estados do Paraná e Santa Catarina. Assemelha-se bastante a Miconia doriana Cogn., já que ambas possuem tricomas estrelados sobre os ramos e hipanto, folhas com o ápice caudado, com a face adaxial glabra e face abaxial com as nervuras unidas por membrana na base. Essas espécies diferem porque em Miconia doriana as flores são 5-6-meras, com 12-20 estames e as bractéolas são caducas, enquanto que em Miconia paniculata as flores são sempre 5-meras, com 10 estames e as bractéolas são persistentes (Goldenberg 2009). Assemelha-se também a Miconia pusilliflora (DC.) Naudin, da qual difere principalmente pela deiscência das anteras, que ocorre através de uma longa abertura longitudinal em M. pusilliflora.

Miconia racemifera (DC.) Triana, Trans. Linn. Soc. London 28 (1): 119. 1871.

Figura $2 \mathrm{a}-\mathrm{b}$

Arbustos ou arvoretas, 3,5-8 $\mathrm{m}$ alt.; ramos, pecíolo, inflorescência e hipanto com tricomas dendrítico-ferrugíneos ca. $0,3 \mathrm{~mm}$ compr., mas alguns braços muito longos, ca. $1 \mathrm{~mm}$ compr. Pecíolo 0,7-1,5 cm compr.; lâmina 12,4-19,8 × 5,9-8,2 cm, cartácea, lanceolada ou elíptica, ápice curtamente 


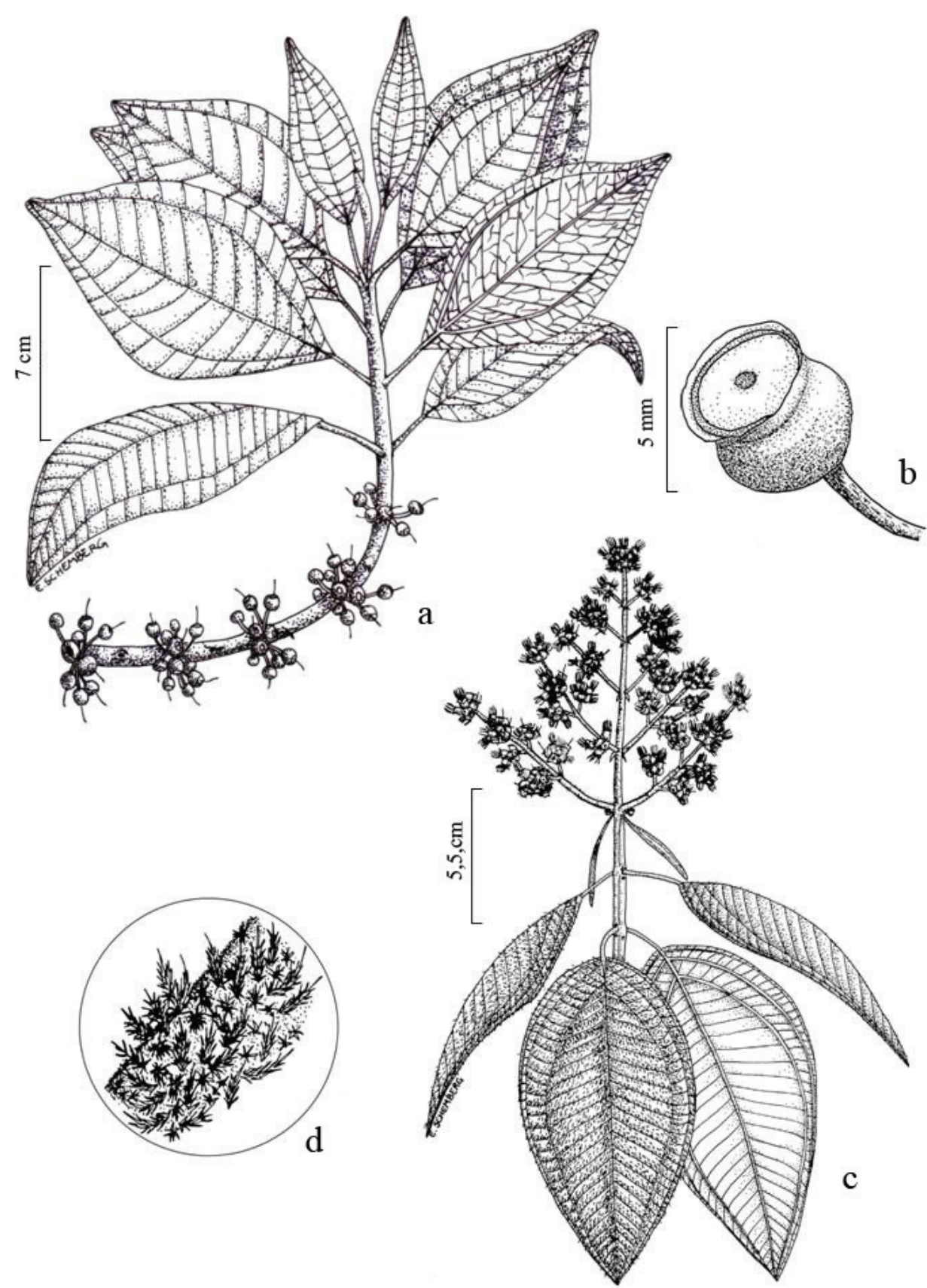

Figura 1. a-b. Henriettea glabra. a. Ramo. b. Fruto. (Sobral \& Sevegnani 9524). c-d. Leandra tetraquetra. c. Ramo. d. Detalhe do indumento que reveste o eixo da inflorescência (Meyer 791).

Figure 1. a-b. Henriettea glabra. a. Branch. b. Fruit. (Sobral \& Sevegnani 9524). c-d. Leandra tetraquetra. c. Branch. d. Detail of indumentum covering the axis of the inflorescence (Meyer 791).

acuminado, base obtusa ou oblíqua, margem esparsamente denticulada, face adaxial geralmente glabra, às vezes recoberta por tricomas dendríticos ca. $0,5 \mathrm{~mm}$ diâm. sobre a nervura central, face abaxial com tricomas dendrítico-ferrugíneos ca. $0,3 \mathrm{~mm}$ compr., alguns braços muito longos, ca. $0,7 \mathrm{~mm}$ compr., nervuras $3+2$, primeiro e segundo pares laterais curtamente suprabasais. Inflorescência em panícula de glomérulos, 9,5-15,5 cm compr.; brácteas ca. $6 \mathrm{~mm}$ compr., lanceoladas, caducas, bractéolas 1,3-4,4 mm compr., lanceoladas, persistentes. Flores 4-meras; hipanto ca. 2,3 mm compr., cálice com lacínias internas $0,5-0,8 \mathrm{~mm}$ compr., lacínias externas ca. 0,9 mm compr., ambas lanceoladas e persistentes; pétalas 3,5-3,7 mm compr., obovadas, ápice emarginado e assimétrico; estames 8 , conectivo 

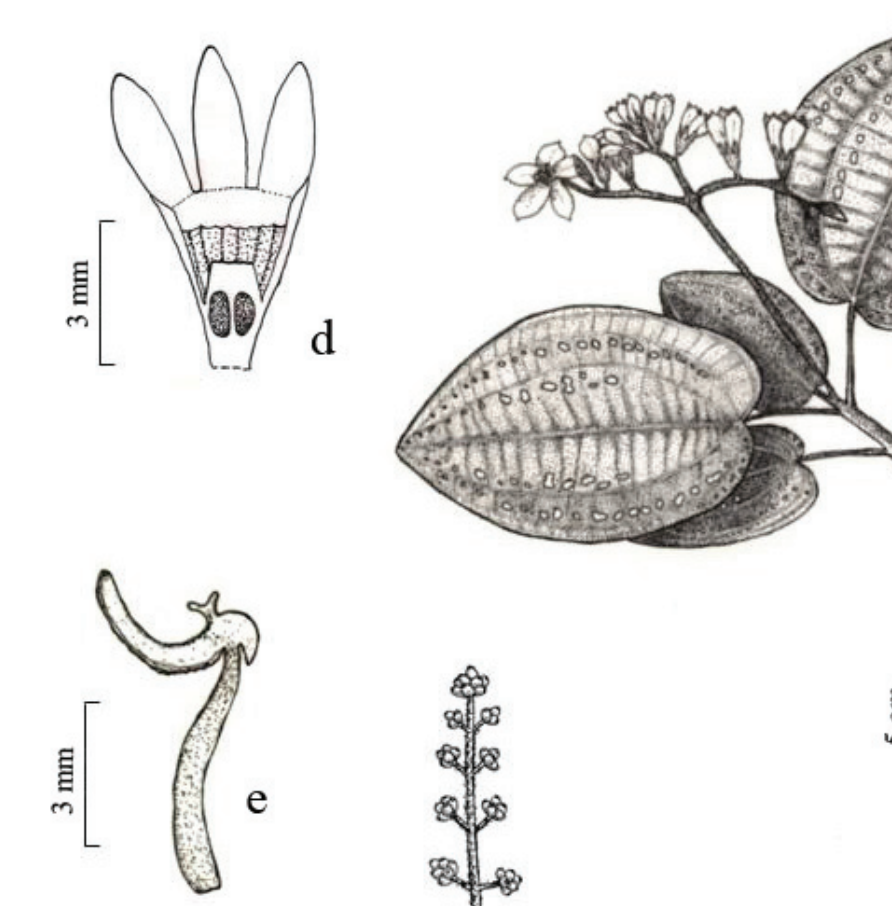
Miconia fasciculata Gardner, que também ocorre em Santa Catarina (Wurdack 1962), pelas folhas grandes, discolores, pelas inflorescências em paniculadas de glomérulos, e indumento de coloração ferrugínea. Em Miconia racemifera as folhas possuem indumento mais denso sobre a face abaxial da lâmina, lacínias externas do cálice lanceoladas e longas, anteras de maior comprimento e inflorescências muito densas. Já em Miconia fasciculata o indumento é mais esparso sob a face abaxial da lâmina foliar, as lacínias externas são triangulares e reduzidas, as anteras possuem 1-1,2 mm compr. e as inflorescências são menos adensadas (Wurdack 1962, Goldenberg 2009).

Salpinga margaritacea (Naudin) Triana, Trans. Linn. Soc. 18: 80. 1871.

Figura $2 \mathrm{c}-\mathrm{e}$

Ervas terrícolas ou rupícolas, ca. $30 \mathrm{~cm}$ alt.; ramos jovens e pecíolos angulosos, tricomas glandulosopubescentes ca. $1 \mathrm{~mm}$ compr. Pecíolo 1-5,5 cm compr.; lâmina 5-12,5 × 2,5-7,5 cm, oval ou oval-oblonga, ápice agudo, base cordada, margem suavemente crenulada, discolor; face adaxial glabra, geralmente provida de manchas ocelares brancas, face abaxial com projeções glandulares pouco conspícuas, nervuras $5+2$ ou 7, basais. Inflorescência em cimeira escorpióide terminal ou axilar, ca. $10 \mathrm{~cm}$ compr.; brácteas ca. 2,3 mm compr., bractéolas ca. 1,3 mm compr., ambas lineraes. Flores 5-meras, pedicelo 1,5-2,9 mm compr.; hipanto ca. $3 \mathrm{~mm}$ compr., provido de projeções glandulares pouco conspícuas, 10-sulcado; cálice com lacínias ca. $4 \times 2 \mathrm{~mm}$, oblongas, ápice agudo; pétalas ca. $11 \times 4,5 \mathrm{~mm}$, obovadas, ápice acuminado; estames 10, anteras 2,5-3 mm compr., poro único, dorsalmente deslocado, conectivo com apêndice dorsal bilobado, um lobo ascendente ca. 0,6 mm compr., ápice obtuso, outro lobo descendente clavado estreitamente cônico ca. 0,5 mm compr., ápice agudo; ovário súpero, ca. 2,3 mm compr.; estilete 2,9-5,9 mm compr. Fruto capsular 3-alado, ca. 4,8 $\times 8 \mathrm{~mm}$, sementes numerosas.

Material selecionado: BRASIL. ParanÁ: Guaraqueçaba, Reserva Natural Salto Morato, 19-I-1998, G. Gatti et al. 234 (UPCB). SANTA Catarina: Brusque, Bairro Águas Claras, 5-XII-2009, T.J. Cadorin 532 (FURB, UPCB). São Francisco do Sul, Vila da Glória, 6-IX-2010, F.S. Meyer \& E.J. Comitti 959 (JOI); F.S. Meyer \& E.J. Comitti 960 (UPCB); F.S. Meyer \& E.J. Comitti 961 (JOI); F.S. Meyer \& E.J. Comitti 962 (UPCB); F.S. Meyer \& E.J. Comitti 963 (JOI).

Salpinga margaritacea já foi reportada para os Estados do Rio de Janeiro e São Paulo (Baumgratz
2009, 2010), mas ocorre também no Paraná e em Santa Catarina, em Floresta Ombrófila Densa bem conservada, próximo a cursos d'água. $\mathrm{O}$ registro de S. margaritacea efetuado por Wurdack (1962) para o Estado de Santa Catarina foi baseado apenas em exemplares com frutos. No entanto, a presença de flores permitiu confirmar a identificação da planta, visto que os apêndices dos estames são importantes para a distinção do gênero em relação a Bertolonia Raddi. Bertolonia acuminata Gardner é a espécie que mais se assemelha a $S$. margaritacea, já que ambas são herbáceas, possuem folhas grandes, cápsulas 3-aladas e ocorrem em Floresta Ombrófila Densa. Essas espécies podem ser diferenciadas, mesmo vegetativamente, pois em $B$. acuminata, as folhas possuem margem denticulada e base aguda ou obtusa enquanto em $S$. margaritacea, a margem das folhas é suavemente crenulada e a base quase sempre cordada. A presença de manchas ocelares brancas distribuídas sobre a face adaxial da lâmina não deve ser considerada um caráter de distinção entre os gêneros, pois essas manchas também podem ocorrer em algumas espécies de Bertolonia (R. Goldenberg obs. pess.).

\section{Agradecimentos}

Os autores agradecem aos curadores dos herbários citados e ao ilustrador Eduardo Schemberg pela confecção de algumas das ilustrações das espécies. F.S. Meyer e M.K. Caddah recebem bolsa de doutorado $\mathrm{CNPq}$, e R. Goldenberg recebe bolsa de produtividade do mesmo órgão. J. Meirelles recebe bolsa de doutorado da CAPES.

\section{Literatura citada}

Ambiente Brasil. 2010. Informações sobre o Estado de Santa Catarina e Paraná. http://www.ambientebrasil. com.br/composer.php3?base =./estadual/index. $\mathrm{html} \&$ conteudo=./estadual/sc.html\#loca $>$ (acesso em 20.03.2010).

Baumgratz, J.F.A. 2009. Salpinga DC. In: S.E. Martins, M.G.L. Wanderley, G.J. Sheperd, A.M. Giulietti \& T.S. Melhem (eds.). Flora Fanerogâmica do Estado de São Paulo. FAPESP, São Paulo, v.6, pp. 124-126.

Baumgratz, J.F.A. 2010. Henriettella. In: R.C. Forzza, J.F.A. Baumgratz, C.E.M. Bicudo, A.A. Carvalho Jr., A. Costa, D.P. Costa, M. Hopkins, P.M. Leitman, L.G. Lohmann, L.C. Maia, G. Martinelli, M. Menezes, M.P. Morim, M.A.N. Coelho, A.L. Peixoto, J.R. Pirani, J. Prado, L.P. Queiroz, V.C. Souza, J.R, Stehmann, L.S. Sylvestre, B.M.T. Walter \& D. Zappi (eds.). Catálogo de Plantas e Fungos do Brasil, v.2. Andrea Jakobsson Estúdio, Rio de Janeiro, pp. 1244. 
Baumgratz, J.F.A. \& Souza, M.L.D. 2009. Leandra Raddi. In: S.E. Martins, M.G.L. Wanderley, G.J. Sheperd, A.M. Giulietti \& T.S. Melhem (eds.). Flora Fanerogâmica do Estado de São Paulo. FAPESP, São Paulo, v.6, pp. 32-68.

Baumgratz, J.F.A., Bernardo, K.F.R., Chiavegatto, B., Goldenberg, R., Guimarães, P.J.F., Kriebel, R., Martins, A.B., Michelangeli, F.A., Reginato, M., Romero, R., D'el Rei Souza, M.L. \& Woodgyer, E. 2010. Melastomataceae. In: R.C. Forzza, J.F.A. Baumgratz, C.E.M. Bicudo, A.A. Carvalho Jr., A. Costa, D.P. Costa, M. Hopkins, P.M. Leitman, L.G. Lohmann, L.C. Maia, G. Martinelli, M. Menezes, M.P. Morim, M.A.N. Coelho, A.L. Peixoto, J.R. Pirani, J. Prado, L.P. Queiroz, V.C. Souza, J.R, Stehmann, L.S. Sylvestre, B.M.T. Walter \& D. Zappi (eds.) . Catálogo de Plantas e Fungos do Brasil, v.2. Andrea Jakobsson Estúdio, Rio de Janeiro, pp. 1236-1278.

Camargo, E.A. \& Goldenberg, R. 2007. Leandra seção Leandraria (Melastomataceae) no Estado do Paraná, Brasil. Iheringia, série Botânica 62: 103-111.

Camargo, E.A., Souza, C.M.F., Caddah, M.K. \& Goldenberg, R. 2009. O gênero Leandra, seções Carassanae, Chaetodon, Niangae, Oxymeris e Secundiflorae (Melastomataceae) no Estado do Paraná. Rodriguésia 60: 595-631.

Clausing, G. \& Renner, S.S. 2001. Molecular Phylogenetics of Melastomataceae and Memecylaceae: implications for character evolution. American Journal of Botany 88: 486-498.

Cogniaux, A. 1883-1888. Melastomataceae. In: C.F.P. Martius, A.G. Eichler \& I. Urban (eds.). Flora Brasiliensis. Typographia Regia, Monachii, v.14 (3-4), pp. $1-510$ e $1-655$.

Cogniaux, A. 1891. Melastomataceae. In: A. De Candolle \& C. De Candolle (eds.). Monographiae Phanerogamarum. G. Masson, Paris, v.7, pp. 1-1256.

Fidalgo, O. \& Bononi, V.L. 1984. Técnicas de coleta, preservação e herborização de material botânico (manual no 4). Instituto de Botânica, São Paulo.

Goldenberg, R. 2004. O gênero Miconia (Melastomataceae) no Estado do Paraná, Brasil. Acta Botanica Brasilica 18: 927-947.

Goldenberg, R. 2009. Miconia. Ruiz \& Pav. In: S.E. Martins, M.G.L. Wanderley, G.J. Sheperd, A.M. Giulietti \& T.S. Melhem (eds.). Flora Fanerogâmica do Estado de São Paulo. FAPESP, São Paulo, v.6, pp. 73-103.

Goldenberg, R. 2010. Miconia In: R.C. Forzza, J.F.A. Baumgratz, C.E.M. Bicudo, A.A. Carvalho Jr., A. Costa, D.P. Costa, M. Hopkins, P.M. Leitman, L.G. Lohmann, L.C. Maia, G. Martinelli, M. Menezes, M.P. Morim, M.A.N. Coelho, A.L. Peixoto, J.R. Pirani, J. Prado, L.P. Queiroz, V.C. Souza, J.R, Stehmann, L.S. Sylvestre, B.M.T. Walter \& D. Zappi (eds.). Catálogo de Plantas e Fungos do Brasil, v.2. Andrea Jakobsson Estúdio, Rio de Janeiro, pp. 1255-1263.
Goldenberg, R., Souza, C.M.F. \& Dequech, H.B. 2005. Clidemia, Ossaea e Pleiochiton (Melastomataceae) no Estado do Paraná, Brasil. Hoehnea 32: 453-466.

Junior, V.A.P. 1991. Aspectos geográficos de Santa Catarina. Editora da Universidade Federal de Santa Catarina, Florianópolis.

Klein, R.M. 1978. Mapa fitogeográfico do Estado de Santa Catarina. In: R. Reitz. (ed.). Flora Ilustrada Catarinense. Herbário Barbosa Rodrigues, Itajaí, pp. 1-24.

Klein, R.M. 1979. Ecologia da flora e vegetação do Vale do Rio Itajaí. Sellowia 31: 1-165.

Klein, R.M. 1980. Ecologia da flora e vegetação do Vale do Rio Itajaí - continuação. Sellowia 32: 166-389.

Maack, R. 2002. Geografia física do Estado do Paraná. 3 ed. Imprensa Oficial, Curitiba.

Martins, A.B. 2009a. Melastomataceae. In: S.E. Martins, M.G.L. Wanderley, G.J. Sheperd, A.M. Giulietti \& T.S. Melhem (eds.). Flora Fanerogâmica do Estado de São Paulo. FAPESP, São Paulo, v.6, pp. 1-4.

Martins, A.B. 2009b. Henriettella Naudin. In: S.E. Martins, M.G.L. Wanderley, G.J. Sheperd, A.M. Giulietti, T.S. Melhem (eds.). Flora Fanerogâmica do Estado de São Paulo. FAPESP, São Paulo, v.6, pp. 24-26.

Meyer, F.S., Guimarães, P.J.F. \& Goldenberg R. 2010. Tibouchina (Melastomataceae) do Estado do Paraná, Brasil. Rodriguésia 61: 615-638.

Meyer, F.S. \& Goldenberg, R. 2012. Aciotis, Acisanthera, Marcetia, Microlepis, Pterolepis e Siphanthera (Melastomataceae, Melastomeae) no Estado do Paraná, Brasil. Rodriguésia 63: 293-303.

Renner, S.S. 1993. Phylogeny and classification of the Melastomataceae and Memecylaceae. Nordic Journal of Botany 13: 519-539.

Silva, K.C. \& Baumgratz, J.F.A. 2008. Henriettea e Henriettella (Melastomataceae, Miconieae) no Estado do Rio de Janeiro, Brasil. Rodriguésia 59: 887-897.

Souza, M.L.D.R. \& Baumgratz, J.F.A. 2010. Leandra In: R.C. Forzza, J.F.A. Baumgratz, C.E.M. Bicudo, A.A. Carvalho Jr., A. Costa, D.P. Costa, M. Hopkins, P.M. Leitman, L.G. Lohmann, L.C. Maia, G. Martinelli, M. Menezes, M.P. Morim, M.A.N. Coelho, A.L. Peixoto, J.R. Pirani, J. Prado, L.P. Queiroz, V.C. Souza, J.R., Stehmann, L.S. Sylvestre, B.M.T. Walter \& D. Zappi (eds.). Catálogo de Plantas e Fungos do Brasil, v.2. Andrea Jakobsson Estúdio, Rio de Janeiro, pp. 1245-1252.

Thiers, B. continuamente atualizado. Index Herbariorum: New York Botanical Garden's Virtual Herbarium. http:// sweetgum.nybg.org/ih/ (acesso em 12.02.2012).

Wurdack, J.J. 1962. Melastomataceae of Santa Catarina. Sellowia 14: 109-217. 
